\title{
Localization of Mycobacterium avium subspecies paratuberculosis in artificially inoculated milk and colostrum by fractionation
}

\author{
L. Van Brandt, ${ }^{* 1}$ K. Coudijzer, ${ }^{*}$ G. Vlaemynck, ${ }^{*}$ M. Hendrickx,† C. Michiels, $\ddagger$ W. Messens, ${ }^{*}$ L. Herman, ${ }^{*}$ \\ and J. De Block* \\ *Institute for Agricultural and Fisheries Research (ILVO), Technology and Food Science Unit, Brusselsesteenweg 370, 9090, Melle, Belgium \\ †Laboratory of Food Technology, and \\ łLaboratory of Food Microbiology, Leuven Food Science and Nutrition Research Centre (LFoRCe), Department of Microbial and Molecular \\ Systems (M2S), Katholieke Universiteit Leuven, B-3001 Heverlee, Belgium
}

\begin{abstract}
The purpose of the study was to determine the distribution of Mycobacterium avium ssp. paratuberculosis (MAP) across the main milk and colostrum fractions (cream, curd, and whey). Raw milk and colostrum were inoculated with 1 of 2 MAP strains, ATCC 19698 or S-23, yielding initial concentrations of $10^{6}$ to $10^{7} \mathrm{cfu} /$ $\mathrm{mL}$. After fractionation, for milk as well as for colostrum, 80 to $90 \%$ of the recovered MAP cells were found in the curd fraction and 10 to $20 \%$ in the cream fraction. Total MAP colony counts in milk whey were 4 to $5 \log _{10}$ units lower than colony counts of inoculated milk. In colostrum, colony counts were 2 to $3 \log _{10}$ units lower in whey than in inoculated colostrum. Because of the slow growth of MAP and to proceed more smoothly with set-up and optimization of the method, luminescent MAP strains were used. The high correlation coefficient $(\mathrm{r}=0.960)$ between colony counts and luminescence measurements showed that the use of luminescent MAP strains during method development was plausible.
\end{abstract}

Key words: paratuberculosis, colostrum, milk, transmission

\section{INTRODUCTION}

Mycobacterium avium ssp. paratuberculosis (MAP) is the causative agent of Johne's disease in cattle and other ruminants (Cocito et al., 1994; Falkinham, 1996; Collins, 1997). Johne's disease is a chronic enteric diarrheal disease that is increasing in incidence in the developed and developing world and will continue to increase unless efficient control measures are established. Infection with MAP generally occurs during the first 6 mo to 1 yr of a calf's life (but can occur later), primarily through the ingestion of MAP from

Received November 11, 2009.

Accepted June 11, 2010.

${ }^{1}$ Corresponding author: Leen.vanbrandt@ilvo.vlaanderen.be contaminated milk or colostrum or fecal contamination of the environment. After a long incubation phase that can last more than 2 to $3 \mathrm{yr}$ in cattle, the infection results in disease. The younger the animal at the time of first infection with MAP, the more likely it is to develop a clinical disease condition. In the clinical stage of Johne's disease, infection with MAP causes chronic diarrhea, reduction in milk production, and weight loss, despite normal appetite (Chiodini et al., 1984), all of which cause huge economic losses for the farmer, both in terms of milk yield and slaughter value (Benedictus et al., 1987; Hutchinson, 1996; Nordlund et al., 1996; Johnson-Ifearulundu et al., 2000; Hasonova and Pavlik, 2006; Groenendaal and Wolf, 2008; Smith et al., 2009). Symptomatically, Johne's disease shows similarities to Crohn's disease in humans (Chiodini, 1989; Greenstein, 2003), which has led to the suggestion of a possible involvement of MAP in Crohn's disease (Chamberlin et al., 2001; Hermon-Taylor and Bull, 2002). When appropriate validated methods are used, MAP is isolated from tissues from most Crohn's patients (HermonTaylor, 2009). Recent studies have identified more than 30 significant loci related to susceptibility to Crohn's disease that are consistent with the involvement of intracellular bacterial pathogens, including mycobacteria, in disease causation (Barrett et al., 2008; HermonTaylor, 2009). Although a causal link between MAP and Crohn's disease has not been proven, MAP could be considered a suspected human pathogen, which indicates the necessity for consideration of potential routes of human exposure to MAP (Abubakar et al., 2007; Feller et al., 2007; Waddell et al., 2008). The economic impact of Johne's disease and the possible role of MAP in Crohn's disease in humans are important reasons for intervention to eradicate MAP from the environment of the farm and the milk. To the best of our knowledge, no research has been published on the association of MAP with the main fractions of milk and colostrum. This information could be useful to the dairy industry, both concerning the eradication of paratuberculosis on 
the farm as well as the transmission of MAP to humans via dairy products.

Mycobacterium avium ssp. paratuberculosis is difficult to study because of its extremely slow growth, the requirement of very specific laboratory conditions (Falkinham, 1996), the need for expensive mycobactinsupplemented media, and the risk for overgrowth by other microorganisms. To proceed more smoothly with set-up and optimization of the method, luminescent MAP strains, provided by WIV Pasteur Institute (Brussels, Belgium; Rosseels et al., 2006), were used as an alternative to time- and labor-intensive plating. To prevent overgrowth, gamma-irradiated milk and colostrum were used. The purpose of the study was to determine the distribution of MAP across the main milk or colostrum fractions (i.e., cream, curd, or whey). This was performed by artificially inoculating milk and colostrum with the luminescent MAP strains, and then fractionating the milk and colostrum into cream, whey, and curd. These fractions were then analyzed for colony count and luminescence to determine the extent to which MAP associated with each fraction.

\section{MATERIALS AND METHODS}

\section{Bacterial Strains}

Two luminescent MAP strains (reference strain ATCC 19698, and strain S-23, a clinical isolate of bovine origin) were obtained from the WIV Pasteur Institute (Rosseels et al., 2006). These strains were transformed with plasmid pSMT1 encoding the luxAB genes from Vibrio harveyi; the plasmid also contains a hygromycinresistance gene as a selectable marker. The strains were grown at $37^{\circ} \mathrm{C}$ for 13 weeks in Middlebrook $7 \mathrm{H} 9$ broth (Difco, West Molesey, UK), supplemented with oleic acid-albumin-dextrose-catalase (OADC, 10\%; Becton Dickinson Ltd., Oxford, UK), mycobactin J (2 $\mu \mathrm{g} /$ mL; Allied Laboratories Inc., Synbiotics Europe SAS, Lyon, France), and hygromycin B $(100 \mu \mathrm{g} / \mathrm{mL}$; Roche Diagnostics, Vilvoorde, Belgium). To determine when to take MAP from culture for the fractionation experiment, growth curves of the 2 strains were recorded by measuring optical density (OD, at $610 \mathrm{~nm}$ ), colony counts $(\mathrm{cfu} / \mathrm{mL})$, and luminescence (relative light units, RLU) at different points during $13 \mathrm{wk}$ of incubation. For the fractionation experiment, cultures were used in their exponential growth phase, when the luminescence was high. At this point, both strains were recovered from $20 \mathrm{~mL}$ of the liquid cultures by centrifugation (15 min, 9,500 $\times g$ ) and washed in PBS to prepare the stock suspension for inoculation. The MAP suspensions were syringed 20 times through a $0.8-\times 40-\mathrm{mm}$ needle $($ Bec- ton Dickinson Microbiology Systems, Franklin Lakes, NJ) to minimize clumping (O'Connor et al., 1983).

\section{Milk and Colostrum}

Raw milk was collected from a stirred cooling tank of a local farm without a MAP history. Colostrum was provided by Biopole S.A. (Les Isnes, Belgium). Raw milk and colostrum were gamma-irradiated in bulk (dose of 15 kGy; Sterigenics, Fleurus, Belgium) to avoid interference by bacterial contamination from the raw milk and colostrum during MAP culture. After irradiation, sterility was tested by performing total bacterial counts in plate count agar (incubation at $37^{\circ} \mathrm{C}$ for 3 d). Irradiated milk and colostrum were also tested for the presence of MAP by plating serial dilutions of the samples on Middlebrook 7H10 agar supplemented with OADC (10\%) and mycobactin $\mathrm{J}(2 \mu \mathrm{g} / \mathrm{mL})$. The agar plates were packed in sterile plastic bags and incubated at $37^{\circ} \mathrm{C}$ for $6 \mathrm{wk}$. Until used, irradiated milk and colostrum were stored at $-80^{\circ} \mathrm{C}$ in aliquots of $500 \mathrm{~mL}$.

\section{Fractionation and Sample Preparation}

Milk and colostrum were left to defrost overnight at $4^{\circ} \mathrm{C}$. The declumped MAP suspensions were added to $20 \mathrm{~mL}$ of gamma-irradiated milk or colostrum at a temperature of $37^{\circ} \mathrm{C}$ up to initial concentrations of $10^{6}$ to $10^{7} \mathrm{cfu} / \mathrm{mL}$. To allow association of MAP bacteria with the different milk or colostrum components, inoculated samples were left in a water bath at $37^{\circ} \mathrm{C}$ for $1 \mathrm{~h}$ and stored overnight at $4^{\circ} \mathrm{C}$. After keeping the samples at $40^{\circ} \mathrm{C}$ for $1 \mathrm{~h}$, cream was isolated by centrifugation $(974$ $\times g, 36 \mathrm{~min}, 4^{\circ} \mathrm{C}$ ). For the luminescence measurements, cream was diluted up to the initial volume of $20 \mathrm{~mL}$ by resuspension in sterile skim milk $\left(40^{\circ} \mathrm{C} ; 10 \%\right.$ solution in sterile water, Oxoid). The remaining skim milk or colostrum was left to curdle at $33^{\circ} \mathrm{C}$ for $30 \mathrm{~min}$ by adding $0.03 \%$ rennet, after which the curd was cut into small pieces with a sterile knife. After $1 \mathrm{~h}$, curd and whey were separated by centrifugation $(974 \times g, 5$ min). As with cream, curd was diluted up to a volume of $20 \mathrm{~mL}$ and the mixture was homogenized by aspirating and expelling it several times through a sterile syringe with a $1.2-\times 50-\mathrm{mm}$ needle (Becton Dickinson Microbiology Systems). The remaining whey was not diluted. Luminescence of whey and diluted curd were measured; the dilution of cream and curd was taken into account when calculating the luminescence in each sample. Three repetitions were performed for milk and colostrum and for both strains. Each strain was tested in a separate experiment starting from the same sterilized milk and colostrum sample. 


\section{Determination of Total MAP Counts in Milk or Colostrum and the Resulting Fractions}

Total MAP counts in milk or colostrum and the resulting fractions were determined by plating the samples [100 $\mu \mathrm{L}$ of subsequent dilutions (1:10) in $1 / 4$ strength Ringer solution (Oxoid)] on Middlebrook 7H10 agar supplemented with OADC (10\%), mycobactin J (2 $\mu \mathrm{g} /$ $\mathrm{mL})$, and hygromycin B $(100 \mu \mathrm{g} / \mathrm{mL})$. All agar plates were packed in sterile plastic bags and incubated at $37^{\circ} \mathrm{C}$ for $6 \mathrm{wk}$. A representative number of typical colonies was confirmed by PCR (Herman et al., 2005). The dilutions of cream and curd were taken into account when calculating the number of colony-forming units in each sample $(\mathrm{cfu} / \mathrm{mL})$.

To assess the quantities of the inoculated MAP bacteria that end up in the entirety of each fraction, the mean weight of each fraction was determined in a separate experiment, similar to that described above, performed in 6 repetitions for milk as well as colostrum.

\section{Luminescence Measurements}

Luminescence was measured in a Lumac Biocounter M 2010 (Celsis, Landgraaf, the Netherlands) with 1\% $n$-decyl-aldehyde (decanal) (Sigma-Aldrich, St. Louis, $\mathrm{MO}$ ) in ethanol as a substrate, by adding $30 \mu \mathrm{L}$ of decanal to $270 \mu \mathrm{L}$ of the sample; the sample was mixed vigorously and luminescence was determined instantly by integrating luminescence during $60 \mathrm{~s}$. A delay of $5 \mathrm{~s}$ was maintained between adding the substrate and the luminescence measurement. Luminescence measurements were performed in triplicate.

\section{Determination of Immunoglobulins in Colostrum and Colostrum Whey}

Immunoglobulin content of colostrum and colostrumderived whey were measured according to the International Dairy Federation Standard 178:1996 (International Dairy Federation, 1996) for the determination of the acid-soluble $\beta$-lactoglobulin content of milk and heat-treated milk by reversed-phase HPLC, with minor modifications to be able to test colostrum and detect Ig with this procedure. Instead of diluting $20 \times$ (as was done in the procedure for raw milk), colostrum and colostrum whey were diluted $40 \times ; 20 \mu \mathrm{L}$ was injected in the HPLC system. A Perkin Elmer Series 200 system (Perkin Elmer, Waltham, MA) was used. Separation was performed on a PLRP-S column $(150 \times 4.6 \mathrm{~mm}$; Polymer Laboratories Ltd., Church Stretton, UK) with 8- $\mu \mathrm{m}$ particle size, $300-\AA$ pore size, and packed with polystyrene divinyl benzene. For HPLC, eluent A was water containing $0.1 \%$ trifluoroacetic acid (vol/vol) and eluent B was acetonitrile containing $0.1 \%$ trifluoroacetic acid ( $\mathrm{vol} / \mathrm{vol})$. Using the total peak area of the $\beta$-lactoglobulin peaks and accepting the same absorption at $205 \mathrm{~nm}$ for Ig as for $\beta$-lactoglobulin, the concentration of Ig in colostrum and colostrum whey was determined based on the peak area obtained for Ig.

To confirm whether immunoglobulins maintained their activity, colostrum and colostrum whey were tested in a preliminary experiment with the Bio-X Diagnostics Respiratory Trivalent ELISA kit (BIO K 243, Jemelle, Belgium). This kit enables the evaluation of the immune response of cattle to 3 pathogens commonly implicated in bovine respiratory infections: bovine respiratory syncytial virus (BRSV), parainfluenza 3 virus (PI3), and Mycoplasma bovis. Briefly, colostrum and colostrum whey were diluted in the dilution buffer up to $1 / 100,1 / 200,1 / 400,1 / 800,1 / 1,600,1 / 3,200$, $1 / 6,400$, and $1 / 12,800$, added to the appropriate wells of a 96-well microtitration plate, incubated for $1 \mathrm{~h}$, and washed. Then, the conjugate, peroxidase-labeled protein $\mathrm{G}$, was added to the wells. After a second incubation and wash, the enzyme substrate (hydrogen peroxide) and the chromogen (tetramethylbenzidine) were added. The intensity of the resulting color was measured at 450 nm using a Multiskan Ex type 355 microplate reader (Thermo Fisher Scientific, Tournai, Belgium).

\section{Statistical Analysis}

Colony counts of MAP in the inoculated milk or colostrum and the resulting fractions were transformed to $\log _{10}$ counts before statistical analysis. For milk and colostrum separately, a main-effects ANOVA was used to study the effect of fraction (inoculated milk and colostrum, cream, curd, whey) and replicate measurements on $\log _{10}$-transformed bacterial counts. Significant differences within the fraction were assessed by Tukey's post hoc test. A $P$-value $<0.05$ was considered to be statistically significant.

A correlation coefficient was calculated to investigate the relationship between colony counts $(\mathrm{cfu} / \mathrm{mL})$ and luminescence measurements (RLU). All analyses were carried out using Statistica 8.0 (Statsoft Inc., Tulsa, $\mathrm{OK})$.

\section{RESULTS}

\section{MAP Strains and Growth Curves}

Growth of the luminescent MAP strains was followed by measuring OD, colony counts, and luminescence as a function of time; curves are shown in Figure 1. The detection limit for the measurement of luminescence 

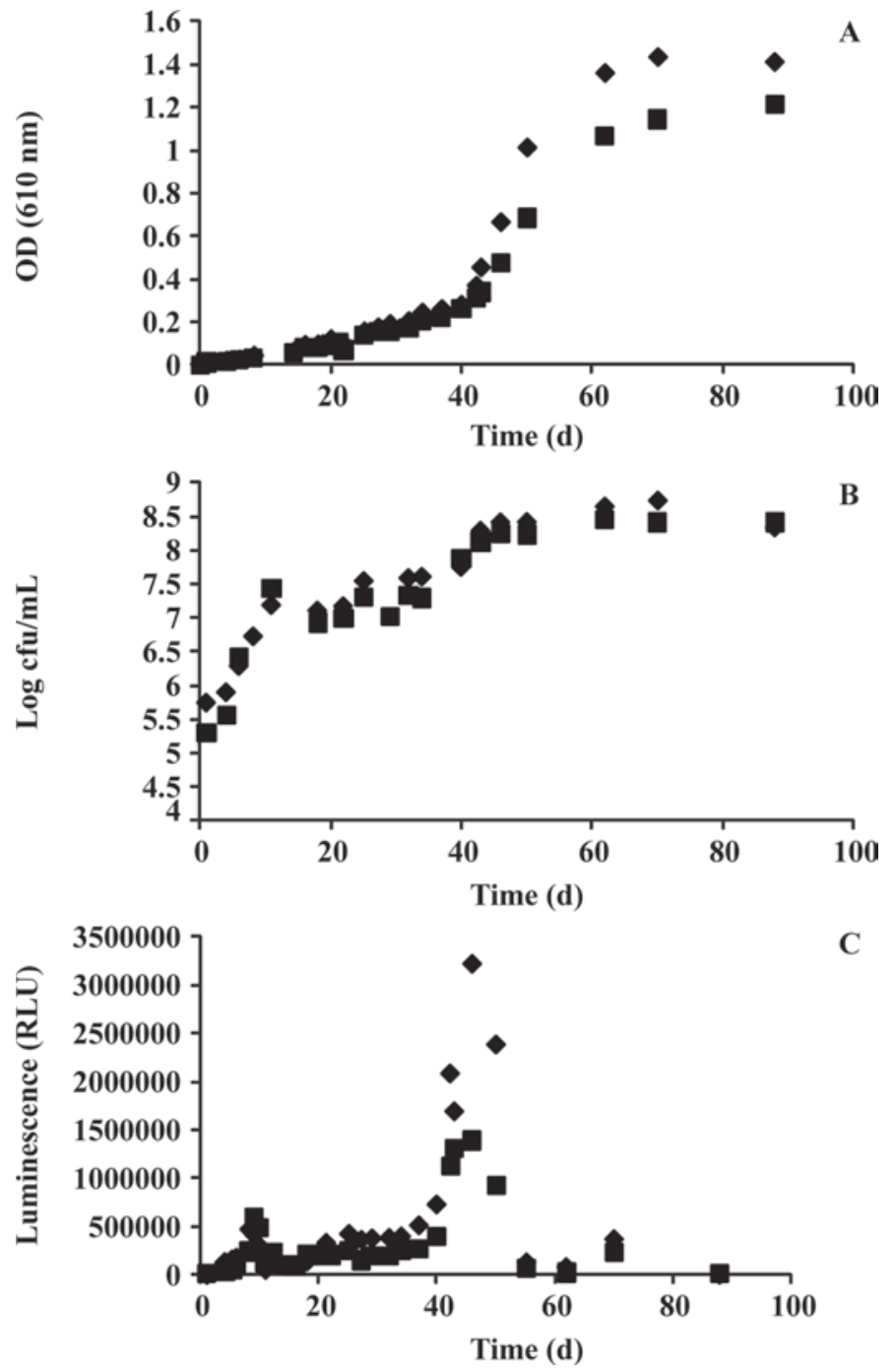

Figure 1. Growth curves in Middlebrook 7H9 broth supplemented with oleic acid-albumin-dextrose-catalase (10\%), mycobactin J (2 $\mu \mathrm{g}$ / $\mathrm{mL})$, and hygromycin $\mathrm{B}(100 \mu \mathrm{g} / \mathrm{mL})$ at $37^{\circ} \mathrm{C}$. (A) Optical density $(\mathrm{OD})$ at $610 \mathrm{~nm},(\mathrm{~B})$ colony counts $\left(\log _{10} \mathrm{cfu} / \mathrm{mL}\right)$, and $(\mathrm{C})$ luminescence (relative light units, RLU) as a function of time for luminescent Mycobacterium avium ssp. paratuberculosis strains S-23 (ם) and ATCC 19698 ( ).

produced by the luminescent bacteria in $1 / 4$ strength Ringer solution was determined to be $10^{2}$ to $10^{3} \mathrm{cfu} / \mathrm{mL}$ for both strains (data not shown). In their exponential growth phase, the strains were inoculated into milk and colostrum. It can be seen that in the exponential growth phase, these curves show higher OD and luminescence values for strain ATCC 19698 than for strain S-23, with a peak luminescence around d 45 for both strains; this approximately coincides with the maximum increase of the OD value. Based on these results, liquid cultures of MAP were used for the fractionation experiment after 6 wk of incubation, when luminescence was high.

\section{Fractionation of Milk or Colostrum Inoculated with MAP}

The raw milk and colostrum used in these experiments were irradiated to eliminate the bacterial contamination and it was shown that the irradiation procedure was successful; no colonies were detected by performing total bacterial counts of the irradiated milk and colostrum (results not shown). In addition, no MAP was detected in the irradiated milk or colostrum used for the experiment (results not shown).

The results of the fractionation of inoculated milk and colostrum are shown in Table 1. The MAP strains were inoculated at a level of approximately $10^{6}$ to $10^{7}$ $\mathrm{cfu} / \mathrm{mL}$. For each fraction, luminescence was measured (data not shown). Colony counts in the entirety of each fraction (mean $\log _{10} \mathrm{cfu} \pm \mathrm{SD}$ ) are given in Table 1 for both MAP strains. Colony counts in the entire fractions were assessed taking into account the weight obtained for each fraction, as indicated in Table 1 . The weights of whole milk, milk cream, milk whey, and milk curd were $20.15,1.47,3.04$, and $15.27 \mathrm{~g}$, respectively. The weights of whole colostrum, colostrum cream, colostrum whey, and colostrum curd were 20.41, 2.56, 8.79, and $8.76 \mathrm{~g}$, respectively. As mentioned, the cream and the curd resulting from centrifugation were suspended in sterile skim milk up to a volume of $20 \mathrm{~mL}$ after which luminescence measurement and plating were carried out. This dilution factor was taken into account in the representation of the results in Table 1.

Most of the inoculated MAP were found in cream and curd; considerably fewer MAP bacteria were found in whey, for milk as well as for colostrum fractionation. Considering the S-23 and ATCC 19698 bacteria recovered from the 3 fractions, about 88 and $80 \%$ were found in the curd fraction of milk, respectively. In the curd fraction of colostrum, about $84 \%$ of the recovered S-23 bacteria and about $80 \%$ of the recovered ATCC 19698 bacteria were found. In all cases, the total MAP colony counts in the curd fraction were not significantly different from those in the inoculated samples $(P>0.05)$.

About 12 and $20 \%$ of the recovered S-23 and ATCC 19698 bacteria, respectively, were found in the cream fraction of milk. In the cream fraction of colostrum, about $16 \%$ of the recovered S-23 bacteria and about $20 \%$ of the recovered ATCC 19698 bacteria were found.

Preliminary fractionation experiments had shown that luminescence values in whey were considerably lower compared with those in cream and curd. Therefore, whey was not diluted with skim milk, to allow detection of low MAP levels. Indeed, luminescence values of milk whey were below the detection limit for ATCC 19698 (results not shown), but colonies could be counted, indicating a difference of about 4 to $5 \log _{10}$ 
Table 1. Colony counts $\left(\log _{10} \mathrm{cfu}\right)$ in fractions after fractionation of milk and colostrum, inoculated with 1 of 2 Mycobacterium avium ssp. paratuberculosis (MAP) strains (S-23 or ATCC 19698), into cream, whey, and curd ${ }^{1}$

\begin{tabular}{|c|c|c|c|c|}
\hline \multirow[b]{2}{*}{ Item } & \multicolumn{4}{|c|}{ Mean $\log _{10}$ cfu $( \pm \mathrm{SD})$ in entire fraction: milkh } \\
\hline & $\begin{array}{l}\text { Whole } \\
\text { milk }\end{array}$ & Cream & $\begin{array}{l}\text { Skim milk } \\
\text { whey }\end{array}$ & $\begin{array}{l}\text { Skim milk } \\
\text { curd }\end{array}$ \\
\hline Fraction weight $(\mathrm{g})$ & $20.15( \pm 0.31)$ & $1.47( \pm 0.11)$ & $3.04( \pm 0.07)$ & $15.27( \pm 0.32)$ \\
\hline S-23 & $7.77( \pm 0.35)^{\mathrm{a}}$ & $\begin{array}{l}6.79( \pm 0.05)^{\mathrm{b}} \\
(11.8 \%)\end{array}$ & $\begin{array}{l}3.45( \pm 0.05)^{\mathrm{c}} \\
(0.005 \%)\end{array}$ & $\begin{array}{l}7.37( \pm 0.64)^{\mathrm{ab}} \\
(88.1 \%)\end{array}$ \\
\hline \multirow[t]{2}{*}{ ATCC 19698} & $8.56( \pm 0.26)^{\mathrm{a}}$ & $\begin{array}{l}7.69( \pm 0.06)^{\mathrm{b}} \\
(19.8 \%)\end{array}$ & $\begin{array}{l}3.83( \pm 0.06)^{\mathrm{c}} \\
(0.003 \%)\end{array}$ & $\begin{array}{l}8.29( \pm 0.05)^{\mathrm{a}} \\
(80.2 \%)\end{array}$ \\
\hline & Whole colostrum & Cream & Skimmed colostrum whey & Skimmed colostrum curd \\
\hline Fraction weight $(\mathrm{g})$ & $20.41( \pm 0.11)$ & $2.56( \pm 0.09)$ & $8.79( \pm 1.82)$ & $8.76( \pm 1.73)$ \\
\hline S- 23 & $7.72( \pm 0.17)^{\mathrm{a}}$ & $6.70( \pm 0.29)^{\mathrm{b}}$ & $5.07( \pm 0.29)^{\mathrm{c}}$ & $7.44( \pm 0.25)^{\mathrm{ab}}$ \\
\hline ATCC 19698 & $8.46( \pm 0.16)^{\mathrm{a}}$ & $\begin{array}{l}7.65( \pm 0.09)^{\mathrm{b}} \\
(19.7 \%)\end{array}$ & $\begin{array}{l}5.14( \pm 0.27)^{\mathrm{c}} \\
(0.1 \%)\end{array}$ & $\begin{array}{l}8.26( \pm 0.11)^{\mathrm{a}} \\
(80.2 \%)\end{array}$ \\
\hline
\end{tabular}

\footnotetext{
${ }^{a-c}$ Means within a row with different superscripts differ $(P<0.05)$.

${ }^{1}$ Values are means $\pm \mathrm{SD}$. The weight of each fraction is indicated. Percentages indicate the relative distribution of the recovered MAP bacteria across the different fractions.
}

units in whey compared with the inoculated milk. For colostrum, the difference was smaller: approximately $3 \log _{10}$ units. Considering the S-23 and ATCC 19698 MAP bacteria recovered from the 3 fractions, only 0.00 and $0.003 \%$, respectively, were recovered from milk whey; in colostrum whey, 0.4 and $0.1 \%$ of the total recovered S-23 and ATCC 19698 bacteria were found, respectively.

The correlation coefficient between colony counts $(\mathrm{cfu} / \mathrm{mL})$ and luminescence measurements (RLU) obtained was $0.960(P<0.001)$. From these results, it can be concluded that it was acceptable to use luminometry during method development as an indication of the part of the inoculated MAP cells that ends up in each fraction.

\section{Determination of Immunoglobulin in Colostrum and Colostrum Whey}

Immunoglobulin content of colostrum and colostrumderived whey were measured by application of the International Dairy Federation Standard 178:1996 (International Dairy Federation, 1996) with minor modifications of the elution gradient to be able to detect Ig with this procedure. The modified elution gradient is shown in Table 2; the most important change is that the time for the increase of the fraction of eluent B from 35 to $65 \%$ was prolonged to $30 \mathrm{~min}$ (instead of $8 \mathrm{~min}$ in the IDF standard). The total concentrations of $\beta$-lactoglobulin measured in colostrum and colostrum whey were 14.72 and $15.74 \mathrm{~g} / \mathrm{L}$, respectively, based on the peak area obtained and the $\beta$-lactoglobulin standard curve. Based on the peak area obtained for the Ig, and accepting the same absorption at $205 \mathrm{~nm}$ for Ig as for $\beta$-lactoglobulin, Ig concentrations of 35.01 and $36.98 \mathrm{~g} / \mathrm{L}$ were derived for colostrum and colostrum whey, respectively. It can be said that all immunoglobulins originally present in colostrum were found in the colostrum whey.

The activity of the Ig in colostrum and colostrum whey was tested in a preliminary experiment by means of an ELISA kit. The results of this procedure showed that the activity of the Ig in colostrum was maintained during the fractionation. Readings of the plate showed that values of colostrum whey corresponded perfectly with those for colostrum (data not shown); there was no destruction of Ig activity during the fractionation procedure.

\section{DISCUSSION}

In this study, milk and colostrum inoculated with MAP were both fractionated into cream, whey, and curd. After fractionation, the distribution of the inocu-

Table 2. Elution gradient of the HPLC method used (slight modifications of the gradient described in IDF standard 178; International Dairy Federation, 1996)

\begin{tabular}{lcc}
\hline $\begin{array}{l}\text { Time } \\
(\min )\end{array}$ & $\begin{array}{c}\text { Eluent A } \\
(\%)\end{array}$ & $\begin{array}{c}\text { Eluent B } \\
(\%)\end{array}$ \\
\hline 0.5 & 65 & 35 \\
1.5 & 65 & 35 \\
31.5 & 35 & 65 \\
32 & 0 & 100 \\
34.5 & 0 & 100 \\
35 & 65 & 35 \\
46.5 & 65 & 35 \\
\hline
\end{tabular}


lated MAP bacteria across the 3 fractions was evaluated based on colony counts. To proceed more smoothly with set-up and optimization of the method, luminescent MAP strains were used to track the distribution across the various fractions. The high correlation coefficient $(\mathrm{r}=0.960, P<0.001)$ between the colony counts and luminescence measurements justifies the use of luminescent MAP strains during method development and indicates that luminescence could be used by other researchers as a quick tool in studies similar to this localization experiment.

Mild centrifugation conditions for fractionation were used to allow a natural separation of the microorganism with its preferred fraction. In milk as well as in colostrum, the highest colony counts were observed in curd and cream, and a considerably smaller number of colonies was encountered in whey. The major association of MAP with curd corresponds with the literature (Spahr and Schafroth, 2001; Donaghy et al., 2004) and can be explained by physical concentration of bacteria in the cheese curd. Next to that, the relatively hydrophobic nature of caseins in curd may trigger hydrophobic interactions with the mycobacterial cell wall, which is also known to be quite hydrophobic. The extent of the observed association of MAP with the milk or colostrum fractions can have consequences in several areas, including public health and animal welfare and health. In regard to cheese making, MAP will concentrate in the curd meant for cheese production. The same applies to the high association of MAP with the cream fraction. The phenomenon of mycobacteria segregating in the lipid-rich fraction of milk is a commonly held belief and is confirmed by this study. Butter and cream contain a considerable amount of milk fat; MAP will concentrate in the fat fraction and end up in butter, cream, and full-fat cheeses for human consumption. However, milk used for butter and cheese production is generally pasteurized, reducing the eventual MAP load in butter and cheese. Although MAP survival in cheese has been reported (Sung and Collins, 2000; Spahr and Schafroth, 2001; Donaghy et al., 2004), to the best of our knowledge, no studies have been published about the survival of MAP during manufacture and storage of butter.

Mycobacterium avium ssp. paratuberculosis associated much less with the whey fraction, and this lesser association with whey was more pronounced for milk than for colostrum. In addition to a possibly naturally higher association with colostrum whey compared with milk whey, another possible explanation is that the curdling of milk and subsequent separation of milk curd and whey is more successful for milk than for colostrum. Indeed, the colostrum whey obtained in this study was more turbid than the milk whey. If small particles of curd are still present in the whey, MAP may be associated with these particles. The portion of the initially inoculated amount of MAP cells that was recovered in the milk whey fraction in this study $(0.003 \%)$ was less than that published by Donaghy et al. (2004). They reported a release of up to $4 \%$ of the inoculated MAP load into the whey fraction during cheese manufacturing. The relatively low association of MAP with the whey fraction is important, especially in the case of colostrum. Roughly, this study shows that MAP-contaminated colostrum can be partially separated into a MAP-containing part (cream and curd) and strongly MAP-reduced whey, containing the Ig. Still, MAP was not completely eliminated in whey. In cattle, MAP is primarily transmitted by the fecaloral route, but direct shedding of MAP into colostrum and milk of infected cows poses a risk as well; feeding colostrum and milk from cows of unknown infection status may also result in further spread of Johne's disease (Nielsen et al., 2008). Because the transfer of MAP via colostrum and milk is an important infection route, MAP would ideally be eliminated from the colostrum or milk before being given to the calf. In any elimination strategy for MAP, sufficient preservation of colostral Ig activity is essential, because the survival of calves depends on it. The low association of MAP with the whey fraction indicated by this study could form the basis of an Ig-preserving elimination strategy for MAP based on colostrum fractionation. Calves should receive a minimum mass of $100 \mathrm{~g}$ of $\mathrm{IgG}$ in the first colostrum feeding within $6 \mathrm{~h}$ after birth (Davis and Drackley, 1998) to protect against pathogenic microorganisms in stables. Because farmers frequently do not know the concentration of IgG in the colostrum being fed, it is currently recommended to feed about 3 to 4 $\mathrm{L}$ of colostrum at first feeding to deliver an adequate amount of Ig to the majority of dairy calves (Hopkins and Quigley, 1997; Tyler et al., 1999). Although there is a lack of knowledge about the exact numbers of MAP that may exist in raw milk and colostrum in reality, inoculum concentrations used in this study $\left(10^{6}\right.$ to $10^{7}$ $\mathrm{cfu} / \mathrm{mL}$ ) considerably exceeded concentrations of MAP that might be expected in naturally infected colostrum (Taylor et al., 1981; Sweeney et al., 1992), but were used to be able to count the bacteria present. Sweeney et al. (1992) reported that the milk of a subclinically infected cow contains 2 to $8 \mathrm{cfu} / 50 \mathrm{~mL}$. Because this milk was decontaminated, which implies about 60 to $70 \%$ reduction of the initial amount of MAP present, one could say that 7 to $20 \mathrm{cfu} / 50 \mathrm{~mL}$ were present initially, or 560 to $1,600 \mathrm{cfu}$ of MAP would be present in $4 \mathrm{~L}$ of colostrum (equaling the MAP levels in milk and colostrum for this example). Because, according to the results of this study, 0.1 to $0.4 \%$ of these MAP cells 
will end up in the whey fraction after fractionation, between 0.6 and 6.4 cfu of MAP would be present in $4 \mathrm{~L}$ of reconstituted colostrum after fractionation. The minimum infectious dose for MAP is unknown and will vary from animal to animal. It is not known whether these low concentrations of MAP fed in a single feeding of colostrum represent an infectious dose, triggering clinical disease.

Heat treatment of colostrum could be a logical alternative strategy to prevent transmission of infectious microorganisms, including MAP, but the potential disadvantage of this procedure is the increase in viscosity of colostrum and denaturation of the colostral Ig and loss of its biological activity (Goldsmith et al., 1983; Lindstrom et al., 1994; Tyler et al., 2000; Elfstrand et al., 2002; Godden et al., 2006; McMartin et al., 2006; Trujillo et al., 2007). Contradictory information has been published on this matter but some authors report on using milder heating conditions; for example, $60^{\circ} \mathrm{C}$ for $30 \mathrm{~min}$, with no or only a slight effect on colostrum viscosity and Ig activity (Godden et al., 2003; Ando et al., 2005; Elizondo-Salazar and Heinrichs, 2009a,b). Immunoglobulin in colostrum may be more stable than that in whey, possibly because of a protective effect of milk components such as sugars, proteins, and salts (Back et al., 1979; Timasheff, 1993; Li-chan et al., 1995). However, Chen and Chang (1998) indicated that the difference between Ig stability in colostrum and colostrum whey will be very small when mild pasteurization conditions are applied $\left(<63^{\circ} \mathrm{C}\right.$ for $\left.30 \mathrm{~min}\right)$. Concerning the heat resistance of MAP, Godden et al. (2006) showed no MAP survival in first-milking bovine colostrum after heating at $60^{\circ} \mathrm{C}$ for $60 \mathrm{~min}$ (inoculation of $10^{3} \mathrm{cfu} / \mathrm{mL}$ ), although they warn to be cautious as variability was observed in culture results. It proves difficult to find a satisfying compromise between Ig preservation and MAP inactivation.

Mild pasteurization applied to colostrum whey may maintain sufficient immunological quality, especially when high-quality colostrum (IgG concentration $>50$ $\mathrm{g} / \mathrm{L}$ ) is used, while further reducing the MAP load to a safe level after fractionation. Reconstitution of the resulting whey by adding MAP-free milk components could give farmers a way to independently produce colostrum that is safer to administer to calves and may decrease the initial exposure of calves to MAP, decreasing the spread of infection over time. If the results of this study are used in a practical context, further investigation is required. It has to be confirmed that the results obtained can be extrapolated to natural situations. It would be interesting for future research to repeat this experiment with naturally contaminated colostrum from infected cows to reflect a realistic count of MAP in the various fractions, particularly whey.
The use of heat treatment to prevent colostral disease transmission should be subject to close quality control; large-scale field studies are needed to confirm whether fractionation of colostrum and subsequent mild heating can be adopted on dairy farms without interfering with passive transfer in calves.

\section{ACKNOWLEDGMENTS}

We acknowledge the Institute for the Promotion of Innovation by Science and Technology in Flanders (IWT Flanders, Brussels, Belgium) for financial support, WIV-Pasteur Institute (Brussels, Belgium) for kindly providing the luminescent MAP strains, and Jessy Claeys, Martine Merchiers, and Wouter De Laender (ILVO, Technology and Food Science Unit, Melle, Belgium) for excellent practical assistance.

\section{REFERENCES}

Abubakar, I., D. J. Myhill, A. R. Hart, I. R. Lake, I. Harvey, J. M. Rhodes, R. Robinson, A. J. Lobo, C. S. J. Probert, and P. R Hunter. 2007. A case-control study of drinking water and dairy products in Crohn's disease-Further investigation of the possible role of Mycobacterium avium paratuberculosis. Am. J. Epidemiol. 165:776-783.

Ando, K., M. Koujiya, A. Suzuki, H. Soda, M. Munakata, and Y. Takeda. 2005. Effects of whey preparation processes and heat treatment on bovine colostrum antibody activity. Milchwissenschaft $60: 67-71$.

Back, J. F., D. Oakenfull, and M. B. Smith. 1979. Increased thermal stability of proteins in the presence of sugars and polyols. Biochemistry 18:5191-5196.

Barrett, J. C., S. Hansoul, D. L. Nicolae, J. H. Cho, R. H. Duerr, J. D. Rioux, S. R. Brant, M. S. Silverberg, K. D. Taylor, M. M. Barmada, A. Bitton, T. Dassopoulos, L. W. Datta, T. Green, A. M. Griffiths, E. O. Kistner, M. T. Murtha, M. D. Regueiro, J. I. Rotter, L. P. Schumm, A. H. Steinhart, S. R. Targan, R. J. Xavier, C. Libioulle, C. Sandor, M. Lathrop, J. Belaiche, O. Dewit, I. Gut, S. Heath, D. Laukens, M. Mni, P. Rutgeerts, A. Van Gossum, D. Zelenika, D. Franchimont, J. P. Hugot, M. de Vos, S. Vermeire, E. Louis, L. R. Cardon, C. A. Anderson, H. Drummond, E. Nimmo, T. Ahmad, N. J. Prescott, C. M. Onnie, S. A. Fisher, J. Marchini, J. Ghori, S. Bumpstead, R. Gwilliam, M. Tremelling, P. Deloukas, J. Mansfield, D. Jewell, J. Satsangi, C. G. Mathew, M. Parkes, M. Georges, and M. J. Daly. 2008. Genome-wide association defines more than 30 distinct susceptibility loci for Crohn's disease. Nat. Genet. 40:955-962.

Benedictus, G., A. A. Dijkhuizen, and J. Stelwagen. 1987. Economic losses due to paratuberculosis in dairy cattle. Vet. Rec. 121:142146.

Chamberlin, W., D. Y. Graham, K. Hulten, H. M. T. El-Zimaity, M. R. Schwartz, S. Naser, I. Shafran, and F. A. K. El-Zaatari. 2001. Review article: Mycobacterium avium ssp. paratuberculosis as one cause of Crohn's disease. Aliment. Pharmacol. Ther. 15:337346.

Chen, C. C., and H. M. Chang. 1998. Effect of thermal protectants on the stability of bovine milk immunoglobulin G. J. Agric. Food Chem. 46:3570-3576.

Chiodini, R. J. 1989. Crohn disease and the mycobacterioses-A review and comparison of 2 disease entities. Clin. Microbiol. Rev. 2:90-117.

Chiodini, R. J., H. J. Vankruiningen, and R. S. Merkal. 1984. Ruminant paratuberculosis (Johne's disease)-The current status and future prospects. Cornell Vet. 74:218-262. 
Cocito, C., P. Gilot, M. Coene, M. Dekesel, P. Poupart, and P. Vannuffel. 1994. Paratuberculosis. Clin. Microbiol. Rev. 7:328-345.

Collins, M. T. 1997. Mycobacterium paratuberculosis: A potential foodborne pathogen? J. Dairy Sci. 80:3445-3448.

Davis, C. L., and J. K. Drackley. 1998. Colostrum. Pages 179-206 in The Development, Nutrition, and Management of the Young Calf. Iowa State University Press, Ames.

Donaghy, J. A., N. L. Totton, and M. T. Rowe. 2004. Persistence of Mycobacterium paratuberculosis during manufacture and ripening of cheddar cheese. Appl. Environ. Microbiol. 70:4899-4905.

Elfstrand, L., H. Lindmark-Mansson, M. Paulsson, L. Nyberg, and B. Akesson. 2002. Immunoglobulins, growth factors and growth hormone in bovine colostrum and the effects of processing. Int. Dairy J. 12:879-887.

Elizondo-Salazar, J. A., and A. J. Heinrichs. 2009a. Feeding heattreated colostrum or unheated colostrum with two different bacterial concentrations to neonatal dairy calves. J. Dairy Sci. 92:4565-4571.

Elizondo-Salazar, J. A., and A. J. Heinrichs. 2009b. Feeding heat-treated colostrum to neonatal dairy heifers: Effects on growth characteristics and blood parameters. J. Dairy Sci. 92:3265-3273.

Falkinham, J. O. 1996. Epidemiology of infection by nontuberculous mycobacteria. Clin. Microbiol. Rev. 9:177-215.

Feller, M., K. Huwiler, R. Stephan, E. Altpeter, A. Shang, H. Furrer, G. E. Pfyffer, T. Jemmi, A. Baumgartner, and M. Egger. 2007. Mycobacterium avium subspecies paratuberculosis and Crohn's disease: A systematic review and meta-analysis. Lancet Infect. Dis. 7:607-613.

Godden, S., S. McMartin, J. Feirtag, J. Stabel, R. Bey, S. Goyal, L. Metzger, J. Fetrow, S. Wells, and H. Chester-Jones. 2006. Heattreatment of bovine colostrum. II: Effects of heating duration on pathogen viability and immunoglobulin. J. Dairy Sci. 89:34763483.

Godden, S. M., S. Smith, J. M. Feirtag, L. R. Green, S. J. Wells, and J. P. Fetrow. 2003. Effect of on-farm commercial batch pasteurization of colostrum on colostrum and serum immunoglobulin concentrations in dairy calves. J. Dairy Sci. 86:1503-1512.

Goldsmith, S. J., J. S. Dickson, H. M. Barnhart, R. T. Toledo, and R. R. Eitenmiller. 1983. IgA, IgG, IgM and lactoferrin contents of human milk during early lactation and the effect of processing and storage. J. Food Prot. 46:4-7.

Greenstein, R. J. 2003. Is Crohn's disease caused by a mycobacterium? Comparisons with leprosy, tuberculosis, and Johne's disease. Lancet Infect. Dis. 3:507-514.

Groenendaal, H., and C. A. Wolf. 2008. Farm-level economic analysis of the US National Johne's Disease Demonstration Herd Project. J. Am. Vet. Med. Assoc. 233:1852-1858.

Hasonova, L., and I. Pavlik. 2006. Economic impact of paratuberculosis in dairy cattle herds: A review. Vet. Med. (Praha) 51:193-211.

Herman, L., V. De Jonghe, I. Dumon, K. Grijspeerdt, H. Naydenski, and E. D'Haese. 2005. Clumping of Mycobacterium avium ssp. paratuberculosis in milk and feces and growth activation after milk heating. Pages 304-310 in Proc. 8th Int. Colloq. Paratuberculosis, Copenhagen, Denmark. E. J. B. Manning and S. S. Nielsen, ed. http://www.paratuberculosis.org/pubs/proc8/

Hermon-Taylor, J. 2009. Mycobacterium avium subspecies paratuberculosis, Crohn's disease and the doomsday scenario, http://www. gutpathogens.com/content/1/1/15.

Hermon-Taylor, J., and T. Bull. 2002. Crohn's disease caused by Mycobacterium avium subspecies paratuberculosis: A public health tragedy whose resolution is long overdue. J. Med. Microbiol. 51:3-6.

Hopkins, B. A., and J. D. Quigley. 1997. Effects of method of colostrum feeding and colostrum supplementation on concentrations of immunoglobulin G in the serum of neonatal calves. J. Dairy Sci. 80:979-983.

Hutchinson, L. J. 1996. Economic impact of paratuberculosis. Vet. Clin. North Am. Food Anim. Pract. 12:373-381.

International Dairy Federation. 1996. Determination of acid soluble $\beta$-lactoglobulin content-milk and heat treated milk-Reversed- phase HPLC method. FIL-IDF Standard No. 178. Int. Dairy Fed., Brussels, Belgium.

Johnson-Ifearulundu, Y. J., J. B. Kaneene, D. J. Sprecher, J. C. Gardiner, and J. W. Lloyd. 2000. The effect of subclinical Mycobacterium paratuberculosis infection on days open in Michigan, USA, dairy cows. Prev. Vet. Med. 46:171-181.

Li-chan, E., A. Kummer, J. N. Losso, D. D. Kitts, and S. Nakai 1995. Stability of bovine immunoglobulins to thermal treatment and processing. Food Res. Int. 28:9-16.

Lindstrom, P., M. Paulsson, T. Nylander, U. Elofsson, and H. Lindmarkmansson. 1994. The effect of heat treatment on bovine immunoglobulins. Milchwissenschaft 49:67-71.

McMartin, S., S. Godden, L. Metzger, J. Feirtag, R. Bey, J. Stabel, S. Goyal, J. Fetrow, S. Wells, and H. Chester-Jones. 2006. Heat treatment of bovine colostrum. I: Effects of temperature on viscosity and immunoglobulin G level. J. Dairy Sci. 89:2110-2118.

Nielsen, S. S., H. Bjerre, and N. Toft. 2008. Colostrum and milk as risk factors for infection with Mycobacterium avium subspecies paratuberculosis in dairy cattle. J. Dairy Sci. 91:4610-4615.

Nordlund, K. V., W. J. Goodger, J. Pelletier, and M. T. Collins. 1996. Associations between subclinical paratuberculosis and milk production, milk components, and somatic cell counts in dairy herds. J. Am. Vet. Med. Assoc. 208:1872-1876.

O'Connor, R. E., K. N. Ewings, and N. W. Hollywood. 1983. Effect of agitation on bacterial aggregates in pure cultures and raw milk. J. Food Prot. 46:681-685.

Rosseels, V., V. Roupie, D. Zinniel, R. G. Barletta, and K. Huygen. 2006. Development of luminescent Mycobacterium avium ssp. paratuberculosis for rapid screening of vaccine candidates in mice. Infect. Immun. 74:3684-3686.

Smith, R. L., Y. T. Grohn, A. K. Pradhan, R. H. Whitlock, J. S. Van Kessel, J. M. Smith, D. R. Wolfgang, and Y. H. Schukken. 2009. A longitudinal study on the impact of Johne's disease status on milk production in individual cows. J. Dairy Sci. 92:2653-2661.

Spahr, U., and K. Schafroth. 2001. Fate of Mycobacterium avium ssp. paratuberculosis in Swiss hard and semihard cheese manufactured from raw milk. Appl. Environ. Microbiol. 67:4199-4205.

Sung, N., and M. T. Collins. 2000. Effect of three factors in cheese production ( $\mathrm{pH}$, salt, and heat) on Mycobacterium avium ssp. paratuberculosis viability. Appl. Environ. Microbiol. 66:1334-1339.

Sweeney, R. W., R. H. Whitlock, and A. E. Rosenberger. 1992. Mycobacterium paratuberculosis cultured from milk and supramammary lymph nodes of infected asymptomatic cows. J. Clin. Microbiol. 30:166-171.

Taylor, T. K., C. R. Wilks, and D. S. McQueen. 1981. Isolation of Mycobacterium paratuberculosis from the milk of a cow with Johne's disease. Vet. Rec. 109:532-533.

Timasheff, S. N. 1993. The control of protein stability and association by weak interactions with water-How do solvents affect these processes. Annu. Rev. Biophys. Biomol. Struct. 22:67-97.

Trujillo, A. J., N. Castro, J. M. Quevedo, A. Arguello, J. Capote, and B. Guamis. 2007. Effect of heat and high-pressure treatments on microbiological quality and immunoglobulin G stability of caprine colostrum. J. Dairy Sci. 90:833-839.

Tyler, J. W., J. Lakritz, D. E. Hostetler, V. Douglas, D. M. Weaver, B. J. Steevens, J. Holle, and J. Denbigh. 2000. Effect of pasteurization at 76 and 63 degrees $\mathrm{C}$ on the absorption of colostral $\mathrm{IgG}$ in calves. J. Dairy Res. 67:619-623.

Tyler, J. W., S. M. Parish, T. E. Besser, D. C. Van Metre, G. M. Barrington, and J. R. Middleton. 1999. Detection of low serum immunoglobulin concentrations in clinically ill calves. J. Vet. Intern. Med. 13:40-43.

Waddell, L. A., A. Rajic, J. Sargeant, J. Harris, R. Amezcua, L. Downey, S. Read, and S. A. Mcewen. 2008. The zoonotic potential of Mycobacterium avium spp. paratuberculosis - A systematic review. Can. J. Public Health 99:145-155. 